Uden, N. van, Matos Faia, M. de \& Assis-Lopes, L. (1956). J. gen. Microbiol. 15, 151-153

\title{
Isolation of Candida albicans from Vegetable Sources
}

\author{
By N. van UDEN, MARIA de MATOS FAIA \\ AND LILIETTE ASSIS-LOPES \\ Departmento de Micologia, Instituto Botanico, Lisbon and Instituto Superior de \\ Higiene 'Dr Ricardo Jorge', Lisbon, Portugal
}

SUMMARY: Five strains of Candida albicans were isolated from the following vegetable sources: flowers of Ulex sp. (two strains), leaves of Myrtus communis, a sample of 'hongo' and a sample of sour red wine. The five strains show the characteristic properties of Candida albicans including pathogenicity for rabbits. These isolations do not prove that the organism has a saprophytic free-living stage; only that it can at least survive outside an animal host for an appreciable time.

The yeast Candida albicans has its known habitat in the mouth, throat, intestinal tract, and perhaps other inner body surfaces of man, certain mammals and birds, and it can readily be isolated from many healthy individuals. Under special and only partly recognized conditions (diabetes, pregnancy, prostrating diseases, antibiotic treatment) this yeast may cause disease ('moniliasis') of a variety of organs (mouth, intestine, vagina, skin, bronchi, lungs, avian crop). As $C$. albicans has been isolated almost exclusively from man and animals, it is generally assumed that infection with this yeast takes place from man or animal to man or animal by intimate contact. C. albicans has until now been reported as isolated only twice from non-animal sources. According to Skinner (1947) C. aldoi (now considered a synonym of C. albicans) was isolated by Negroni and Fisher from decaying vegetables; and di Menna \& Parle (1954) and di Menna (1955) isolated three strains of C. albicans from two soils in New Zealand.

Among 180 yeast strains which we isolated from plants, vegetable- and dairy-products, five strains belonged to Candida albicans; two were isolated from flowers of furze (Ulex sp.), one from leaves of myrtle (Myrtus communis), one from a sample of 'hongo' (a symbiosis of Acetobacter xylinum with various yeasts used for preparing a popular beverage from sugared tea) and one from sour non-bottled red wine. The two furze plants were located near the top of a hill $(300 \mathrm{~m}$. high) near Vermoil in the Portuguese province of Estremadura. The approximate height of the flowers on the bushes was $1 \mathrm{~m}$. above the ground; the hill was uncultivated and uninhabited by man, but occasionally a small herd of sheep and goats used to pass. The myrtle grew on the slope of the same hill and the leaves from which Candida albicans was isolated were c. $0.5 \mathrm{~m}$. above the ground. The sample of 'hongo' was obtained in Lisbon from a man who had handled this material during several months in passing it every 3 or 4 days to a fresh lot of sugared tea. The wine was purchased in a small shop in Lisbon. 
The five strains form round and slightly oval cells on solid and liquid media. None of the strains formed ascospores when grown on various sporulation media (gypsum blocks, Gorodkowa agar, carrot plugs). On Dalmau plates (Wickerham, 1951) of glucose $(2 \%)$ yeast extract $(0.5 \%)$ peptone $(1 \%)$ agar the formation of pseudomycelium with ball-like clusters of blastospores was observed in all five strains. Besides this type of pseudomycelium, other types as described by Lodder \& Kreger-van Rij (1952) for Candida albicans were seen in various degrees. The present authors did not feel it necessary for the identification of the strains to try to induce the formation of chlamydospores. The fermentation and assimilation tests were done according to Wickerham's (1951) technique with the following results: D-glucose and maltose strongly fermented, D-galactose weakly fermented; sucrose and lactose not fermented. The strains utilized: D-glucose, D-galactose, sucrose, maltose, D-xylose, ethanol, D-mannitol, D-sorbitol and soluble starch; L-arabinose utilized very weakly; nitrate, lactose, raffinose, inositol, inulin are not utilized.

Intravenous inoculation of rabbits with $1 \mathrm{ml}$. of a $1 \%(\mathrm{v} / \mathrm{v})$ suspension of organisms of any of the strains resulted in death of the animals within 4 days with the formation of numerous abscesses in the renal cortex and the brain.

Our 5 strains could be differentiated from Candida stellatoidea and C. claussenii, two species closely related with $C$. albicans. C. stellatoidea does not assimilate sucrose and does not kill rabbits when $1 \mathrm{ml}$. of a $1 \%(\mathrm{v} / \mathrm{v})$ suspension of organisms is inoculated intravenously. C. claussenii does not ferment galactose, is morphologically distinct from $C$. albicans, and is less pathogenic for laboratory animals.

Our findings do not prove that a natural habitat of Candida albicans is on plants and in various vegetable products. It seems more probable that nonanimal substrates like ours may support growth or permit survival of $C$. albicans during considerable time, after being contaminated with the yeast from man or animals. In the case of the wine and the 'hongo' the original infection almost certainly was from man. The plants might have been contaminated by animals (e.g. sheep, goats, birds, rodents, man). As for the time of survival of C. albicans on non-animal substrates, some evidence was obtained by di Menna \& Parle (1954); they isolated $C$. albicans during 9 months from artificially inoculated turf. Our findings show that various vegetable materials may harbour C. albicans, and it is evident that this yeast could be introduced into man or animals on ingestion of those materials.

Three of the five strains we isolated are maintained in the culture collection of the Departamento de Micologia, Instituto Botânico, Lisbon, under the following numbers: 2427 (from Myrtus communis), 2428 (from Ulex sp.), 2491 (from 'hongo'). Cultures of the same strains have been deposited with the Yeast Division of the Centraalbureau voor Schimmelcultures, Delft, Holland.

This work was subsidized by the 'Instituto de Alta Cultura', Lisbon. 


\section{REFERENCES}

Lodder, J. \& Kreger-van RiJ, N. J. W. (1952). The Yeasts. Amsterdam: NorthHolland Publishing Company.

Menna, M. E. DI (1955). A search for pathogenic species of yeast in New Zealand soils. J. gen. Microbiol. 12, 54.

Menna, M. E. di \& Parle, J. N. (1954). Some extra-human occurrences of a pathogenic yeast. Proc. Univ. Otago med. Sch. 32, 2.

Skinner, C. E. (1947). The yeast-like fungi: Candida and Brettanomyces. Bact. Rev. 11, 227.

Wickerham, L. J. (1951). Taxonomy of yeasts. Tech. Bull. U.S. Dep. Agric. No. 1029.

(Received 24, January 1956) 